\section{Triagem de Mutações nos Receptores de Angiotensina II, AGTR1 e AGTR2 e Avaliação dos Polimorfismos C573Te Al166C do Gene AGTRI em Pacientes com Adrenarca Precoce Idiopática}

\section{RESUMO}

Pubarca precoce é o aparecimento de pêlos pubianos antes dos 8 anos em meninas e 9 anos em meninos, sendo sua etiologia mais freqüente a adrenarca precoce idiopática, a longo prazo, associada à síndrome metabólica. Dentre os fatores envolvidos na gênese da adrenarca precoce podemos citar a Angiotensina II (Ang II), a qual promove proliferação celular e esteroidogênese, podendo agir através de dois receptores, o tipo 1 (AT1) e o tipo 2 (AT2). Com o intuito de estudar mutações dos genes dos receptores da Angll, foram avaliadas 50 crianças com diagnóstico de adrenarca precoce idiopática e comparadas ao grupo controle de indivíduos normais. Não foram detectadas mutações dos genes AGTR1 e AGTR2, contudo dois polimorfismos foram identificados no gene AGTR1: o polimorfismo C573T (localizado no exon 5) e o A1 166C (na região 3' não codificadora). A freqüência do alelo polimórfico T573 foi de 35\% nos pacientes e $38 \%$ nos controles. $O$ alelo polimórfico $C 1166$ esteve presente em $24 \%$ dos pacientes e em $26 \%$ dos controles. Não houve diferença significante entre os grupos, assim como não houve correlação entre a freqüência dos polimorfismos C573T e A1 166C e as variáveis clínicas e laboratoriais dos pacientes, ou com sua história familial de síndrome metabólica. (Arq Bras Endocrinol Metab 2006;50/5:893-900)

Descritores: Puberdade precoce; Síndrome plurimetabólica; Receptores de angiotensina; Polimorfismo de conformação de fita simples; Enzimas de restrição do DNA

\section{ABSTRACT}

Mutation Screening in Angiotensin II Receptors, AGTR1 and AGTR2, and Evaluation of AGTR1 Polymorphisms C573T and A1166C in Patients with Premature Adrenarche.

Precocious pubarche is the appearance of pubic hair before the age of 8 years in girls and 9 years in boys. The most frequent etiology is idiopathic precocious adrenarche, suggested, after long-term follow-up, to be associated with metabolic syndrome. One of the factors involved in the genesis of precocious adrenarche is Angiotensin II (Ang II), which promotes cell proliferation and steroidogenesis through type 1 (AT1) and type 2 (AT2) receptors. In order to study Ang II receptors mutations, 50 children with idiopathic precocious adrenarche were evaluated and compared to a control group of normal individuals. Mutations were not detected in the AGTR1 and AGTR2 genes; however, two polymorphisms were identified in the AGTR1 gene: the C573T (exon 5) and the A1166C (3' untranslated region). The polymorphic allele T573 was found in $35 \%$ of the patients and $38 \%$ of controls. The polymorphic allele C1 166 was present in $24 \%$ of the patients and $26 \%$ of controls. There was no statistical difference between groups. There was also no correlation between the polymorphisms and clinical and laboratory findings, as well as their family history of metabolic syndrome. (Arq Bras Endocrinol Metab 2006;50/5:893-900)

Keywords: Precocious puberty; Metabolic syndrome; Angiotensin receptor; Single strand conformational polymorphism; DNA restriction enzyme artigo original

\author{
Mônica S.F. Moura \\ Mônica B. de Melo \\ Carlos Alberto Longui \\ Mylene N. Rocha \\ Osmar Monte
}

\author{
Unidade de Endocrinologia \\ Pediátrica, Departamento de \\ Pediatria e Puericultura, \\ Irmandade da Santa Casa de \\ Misericórdia de São Paulo, e \\ Laboratório de \\ Medicina Molecular, \\ Faculdade de Ciências \\ Médicas da Santa Casa de \\ São Paulo, SP.
}

Recebido em 21/09/04

Revisado em 22/11/05 Aceito em 28/04/06 
A DRENARCA É A MATURAÇÃO FUNCIONAL da glândula adrenal, sendo o termo pubarca indicativo do aparecimento de pêlos pubianos. Classicamente, pacientes portadores de pubarca precoce são crianças com idade menor que 8 anos em meninas e 9 anos em meninos, que iniciaram pilificação genital sem outros sinais de virilização. Esta apresentação clínica tem como etiologia mais freqüente a adrenarca precoce idiopática. Existe avanço da idade óssea, porém sem comprometimento da estatura final. $\mathrm{O}$ diagnóstico diferencial deve incluir doenças como a hiperplasia congênita das adrenais e tumores adrenocorticais virilizantes (1).

$\mathrm{Na}$ vida adulta as pacientes podem apresentar hirsutismo ou evoluir com maior freqüência para síndrome metabólica, caracterizada por hipertensão arterial, diabetes mellitus tipo 2, obesidade, dislipidemia, hiperuricemia e ovários policísticos, associando-se, portanto, a maior risco para doenças cardiovasculares $(2,3)$.

Em condições fisiológicas, o controle de secreção dos esteróides adrenais é feito pelo hormônio adrenocorticotrófico (ACTH), que age nas zonas reticular e fasciculada das adrenais, responsáveis, respectivamente, pela produção predominante de andrógenos e glicocorticóides. A zona glomerulosa é controlada, principalmente, pelo sistema renina-angiotensina, que, por sua vez, regula a produção de mineralocorticóides, em especial a aldosterona (4).

Sabe-se que há outros fatores estimuladores da secreção de andrógenos adrenais, como a insulina e fatores de crescimento "insulina-like" (5). Isto ocorre em parte nos casos em que a ativação da função adrenal é independente de ACTH.

A ativação adrenal se relaciona diretamente com o aumento da concentração de deidroepiandrosterona-sulfato (DHEA-S), seu principal marcador de síntese (6).

A angiotensina II (Ang II) também é considerada um agente estimulador da esteroidogênese adrenal. Seus receptores estão distribuídos nas diferentes camadas, tanto em humanos como em outras espécies, sugerindo que a Ang II possa ser um potencial fator regulador da esteroidogênese (7-10).

A Ang II age através de dois receptores: receptor tipo 1 (ATl) e receptor tipo 2 (AT2). Os receptores contêm sete domínios hidrofóbicos transmembrana e pertencem à superfamília dos receptores ligados à proteína G. As seqüências de aminoácidos deduzidas mostram que estes receptores são estruturalmente diferentes, com homologia de aproximadamente 33\%, mas com efeitos fisiológicos freqüentemente opostos (11).
O ATl é responsável pela maioria dos efeitos da Ang II sobre os órgãos-alvo, como manutenção da pressão arterial através da regulação da contração da musculatura lisa, bem como da homeostase hidroeletrolítica relacionada à secreção de aldosterona e conseqüente retenção de sódio e água $(12,13)$. Além disso, a ativação do receptor $\mathrm{ATl}$ promove a esteroidogênese adrenal, ativação neuronal, transporte de íons, bem como proliferação e crescimento celular. Algumas das ações induzidas pelo ATl são reguladas pelo AT2, o qual antagoniza o efeito proliferativo em vários órgãos como o endotélio, miocárdio e ovários (8).

O gene do ATl humano - AGTRI - está localizado no cromossomo $3 \mathrm{q} 21-25$, possui 5 exons, sendo que toda a região codificadora do ATl está contida no exon 5 (14-16). O AT2 humano é codificado por um único gene, o AGTR2, localizado no cromossomo Xq22-23 (17,18). Este gene possui dois pequenos exons não codificados; dois introns e o exon 3 , que contém toda região codificadora do receptor (19).

Tanto o AT1 quanto o AT2 estão expressos na adrenal em várias proporções e em diferentes regiões. Em humanos, o AT2 é responsável por 10 a 40\% dos sítios de ligação com a Ang II na adrenal (8).

Nas adrenais, mais especificamente, o AT2 está relacionado à morte celular programada (apoptose) durante o desenvolvimento adrenal fetal. Sabe-se que a adrenal fetal produz grande quantidade de DHEA e DHEA-S, devido à não expressão da enzima $3 \beta$ hidroxiesteróide-desidrogenase (3bHSD) neste tecido. Existe grande quantidade de receptores AT2, expressos principalmente no segundo trimestre da gestação; quando estes receptores são ativados, inicia-se o processo de redução do tamanho da glândula, secundário ao desaparecimento da zona fetal por apoptose (20-23).

Este padrão de expressão do $A G T R 2$, com predominância durante a vida fetal e em condições patológicas, indica que a Ang II pode utilizar este receptor em processos de desenvolvimento, diferenciação e em resposta a mecanismos adaptativos a lesões (24).

Considerando-se a possível influência da Ang II na secreção de andrógenos e na sobrevida das células produtoras desses esteróides, além da inter-relação dos dois tipos de receptores da Ang II, neste estudo duas hipóteses foram formuladas. A primeira é de que mutações ativadoras do gene AGTR 1 podem aumentar a secreção de esteróides adrenais, bem como determinar um efeito positivo sobre a proliferação celular, reduzindo a apoptose das células adrenais fetais, com conseqüente aumento de DHEA-S, podendo ser, portanto, um dos responsáveis pelo início precoce da 
adrenarca. Como segunda hipótese, propõe-se que mutações do gene $A G T R 2$ poderiam reduzir a perda de função e conseqüente diminuição da apoptose adrenal, determinando persistência de células adrenais fetais, com características compatíveis com a adrenarca.

Este estudo teve o objetivo de determinar, em pacientes com adrenarca precoce idiopática, a freqüência de mutações nos genes AGTR1 e AGTR2 e sua correlação com sinais e sintomas compatíveis com síndrome metabólica.

\section{CASUÍSTICA E MÉTODOS}

\section{Casuística}

Foram avaliadas 50 crianças com diagnóstico confirmado de adrenarca precoce idiopática após teste de estímulo com $250 \mu \mathrm{g}$ de ACTH, no qual não se observou acúmulo anormal de hormônios precursores da esteroidogênese. Foram excluídas crianças com diagnóstico de hiperplasia adrenal congênita, tumores adrenais, puberdade precoce central, uso de andrógenos exógenos ou doenças do sistema nervoso central que pudessem influenciar no eixo hipotálamo-hipófise-adrenal, como as encefalopatias crônicas, hidrocefalia e traumas cranioencefálicos.

Dentre as crianças avaliadas, 47 eram do sexo feminino e 3 do sexo masculino. A média de idade do início da pubarca nas meninas, referida pelos pais, foi de 5,9 anos ( $\mathrm{DP}=1,1$; intervalo: 3,8 a 7,8 anos) e nos 3 meninos, a idade da pubarca foi inferior a 7 anos, em média 1 a 2 anos entre a pubarca e a avaliação inicial. Em relação à raça, dentre o grupo estudado, 16 crianças eram brancas e 30 eram negras ou pardas (quatro pacientes não tinham caracterização da raça).

No momento da inclusão no estudo, após o consentimento informado dos pais aprovado pelo Comitê de Ética em Pesquisa da Instituição, procedeu-se à coleta de dados clínicos e inquérito sobre os antecedentes mórbidos, pessoais e familiais. A história familial (HF) de síndrome metabólica foi avaliada, sendo que, dos pacientes com adrenarca precoce idiopática, vinte e oito crianças tinham HF positiva, assim considerada quando houvesse pelo menos um familiar (pai, mãe, irmãos, avós paternos ou maternos) com pelo menos dois componentes da síndrome metabólica. Vinte e um pacientes não tinham HF para síndrome metabólica e um não pôde ser avaliado por não haver informações suficientes sobre os pais biológicos.

Em todos os pacientes foram aferidos peso, desvio-padrão do peso para idade e sexo (ZP), estatura, desvio-padrão da estatura para idade e sexo
(ZE), índice de massa corporal (IMC) e desviopadrão do IMC para idade e sexo (ZIMC). As crianças foram acompanhadas com idade óssea e exames clínicos e laboratoriais como glicemia, perfil lipídico (Advia 1650, Bayer) e insulinemia (Immulite 2000, DPC).

Como grupo controle foram incluídos $50 \mathrm{vo}-$ luntários doadores de sangue que compareceram ao Hemocentro da Irmandade da Santa Casa de Misericórdia de São Paulo, constituído por 29 homens e 21 mulheres não obesos (IMC< 30$)$, com idade entre 18 e 56 anos. Dez mulheres e 11 homens eram brancos, e 11 mulheres e 18 homens negros. Os controles não apresentavam história pessoal ou familial de síndrome metabólica. Não foi avaliada a história de pubarca precoce neste grupo controle devido à dificuldade na obtenção deste dado.

\section{Métodos}

Mutações dos genes AGTR1 e AGTR2 foram inicialmente investigadas nos pacientes com adrenarca precoce idiopática através de polimorfismo de conformação de fita simples - SSCP (Novex, Carlsbad, CA), permitindo a identificação de dois polimorfismos no gene AGTRl: o polimorfismo C573T (localizado no exon 5) e o All66C (na região 3' não codificadora), que foram confirmados por seqüenciamento. Tais polimorfismos foram então estudados nos 50 pacientes e nos 50 controles através de digestão enzimática, como descrito a seguir:

\section{Avaliação do polimorfismo C573T}

Foram utilizados os seguintes pares de iniciadores (Invitrogen, Carlsbad, CA) para amplificação do fragmento de 227 pares de bases (pb), localizado na região codificadora do gene AGTR 1: iniciador sense: 5'TTGAGAACACCAATATTACAGTTTG-3' e iniciador anti-sense: 5'-AAGCACAATTGCCATAATTATCTT-3'.

\section{Avaliação do polimorfismo A1 166C}

Foram utilizados os seguintes pares de iniciadores (Invitrogen, Carlsbad, CA) para amplificação de um fragmento de $400 \mathrm{pb}$, localizado na região 3 ' não codificadora do gene AGTRl: iniciador sense: 5'AATTGCAGATATTGTGGACACG-3' e iniciador anti-sense: 5'-GAAAAGTCGGTTCAGTCCAC-3'.

Para a digestão deste produto foi escolhida a enzima de restrição Dde I (New England-Biolabs Inc, ref: R0175S). A amplificação deste fragmento em condições normais, por possuir uma base adenina na posição 1166 , apresenta apenas um sítio de restrição 
para a enzima Dde I. A digestão gera 2 fragmentos (199pb e $201 \mathrm{pb}$ ). O polimorfismo All66C (troca de adenina por citosina) cria um segundo sítio de restrição gerando 3 fragmentos $(201 \mathrm{pb}, 143 \mathrm{pb}$ e $58 \mathrm{pb}$, respectivamente). Assim, três genótipos foram identificados: o homozigoto para o alelo normal Al166 (denominado AA), o homozigoto para o polimorfismo Cl166 (denominado CC) e o heterozigoto, que possui um alelo Al166 e outro C1166 (denominado AC) (figura 2).

\section{Análise estatística}

Utilizou-se o programa SigmaStat for Windows, versão 2.3 (SPSS). O teste $t$-Student foi utilizado para comparação das médias das variáveis contínuas de distribuição paramétrica. Para amostras de distribuição não paramétrica foi aplicado o teste Mann-Whitney (Rank Sum Test). Os resultados descritivos foram expressos em média \pm desvio-padrão. Quando a mesma variável foi avaliada entre três ou mais grupos independentes, foi aplicado o teste $A N O V A$. O teste $Z$ foi utilizado para comparação das variáveis categorizadas, assim como para comparar as proporções de freqüências genotípicas entre os grupos de estudo. Adotou-se um intervalo de confiança de $95 \%$ em todos os testes utilizados, sendo portanto consideradas diferenças significantes quando o valor de $p$ foi menor que 0,05 .
(A)

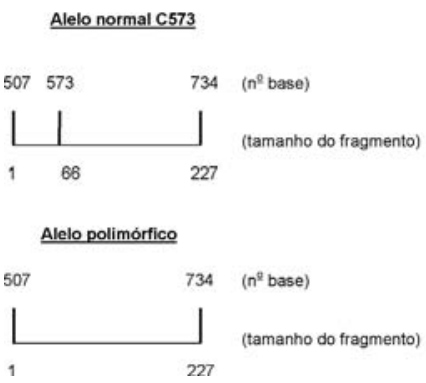

(B)

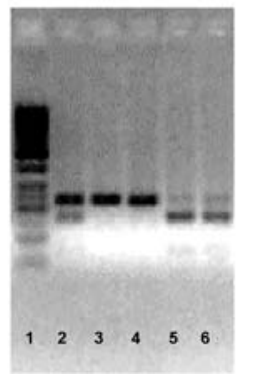

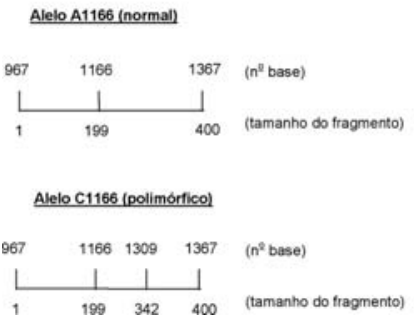

(B)

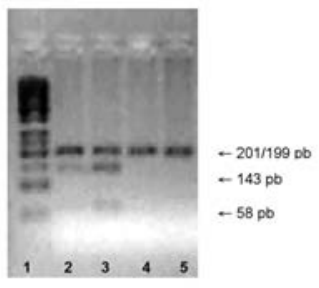

Figura 2. (A) Em condições normais, a amplificação gera um fragmento de 400pb, que por possuir uma base adenina na posição 1166 apresenta um sítio de restrição para a enzima Dde I. A digestão gera 2 fragmentos (199pb e 201pb). O polimorfismo A1166C (troca de adenina por citosina) cria 1 sítio de restrição adicional, gerando 3 fragmentos (199pb, 143pb e 58pb, respectivamente). (B) Exemplo da avaliação do polimorfismo A1 166C do gene AGTR1 por restrição enzimática, com a utilização da enzima Ddel, em pacientes com adrenarca precoce idiopática. 1. Marcador de peso molecular "50bp DNA Ladder", 2. Genótipo AC para o polimorfismo A1166C, 3. Genótipo CC para o polimorfismo A1 166C, 4 e 5. Genótipo AA para o polimorfismo A1166C. 
jejum (> $116 \mathrm{mg} / \mathrm{dL}$ ), e apenas um paciente não obeso tinha concentração de colesterol total elevada.

Quando avaliada a relação glicemia/insulina (G/I) em jejum, foi observado que $10 / 32$ pacientes apresentavam valores sugestivos de resistência insulínica [relação G/I < 7,0; segundo critério proposto por Vuguin e cols., em 2001 (25)]. Destes, apenas um era púbere não obeso e dois tinham ZIMC > 2,0. Posteriormente, os pacientes foram divididos em dois grupos: aqueles com $\mathrm{G} / \mathrm{I} \geq 7,0$ e os com $\mathrm{G} / \mathrm{I}<7,0$. Não houve diferença significante entre os grupos quando comparados estatura de nascimento, ZIMC, concentrações de 17OHP, DHEA-S e colesterol total. As concentrações de insulina em jejum foram mais elevadas no grupo com $\mathrm{G} / \mathrm{I}<7,0$.

\section{Avaliação de mutações nos genes AGTR1 e AGTR2}

Por meio da técnica de SSCP não foram detectadas mutações dos genes $A G T R 1$ e $A G T R 2$. Contudo, dois polimorfismos foram identificados no gene AGTRI: o polimorfismo C573T (localizado no exon 5) e o Al166C (na região 3' não codificadora), que foram confirmados por seqüenciamento.

\section{Avaliação dos polimorfismos C573T e A1166C}

Para o polimorfismo C573T, a freqüência do alelo normal C573 foi de 65\% entre os pacientes com adrenarca precoce e de $62 \%$ no grupo controle; já o alelo polimórfico T573 esteve presente em 35\% dos pacientes e em 38\% dos controles. Para o polimorfismo Al166C a freqüência do alelo normal All66 foi de $76 \%$ entre os pacientes com adrenarca precoce e de $74 \%$ no grupo controle; sendo o alelo polimórfico C1166 detectado em 24\% dos pacientes e em 26\% dos controles.
A análise estatística através do teste de duas proporções (teste $\mathrm{Z}$ ) não identificou diferença significante na distribuição entre os pacientes com adrenarca precoce e os controles para ambos os polimorfismos (tabela 1).

Não houve diferença significante entre os pacientes quando separados pelos genótipos $(\mathrm{CC}, \mathrm{CT}$ e TT para o polimorfismo C573T; AA, AC e CC para o polimorfismo Al 166C), comparando-se as seguintes variáveis: idade da pubarca, ZIMC, DHEA-S, glicemia, insulinemia e colesterol total em jejum, assim como a relação glicemia/insulina (tabela 2). Quando os pacientes foram divididos pela presença ou ausência de história de síndrome metabólica na família, também não foi encontrada diferença entre as proporções dos genótipos para estes polimorfismos (tabela 1).

\section{DISCUSSÃO}

A constatação de que a etiologia da adrenarca precoce ainda não está totalmente estabelecida induziu vários investigadores a avaliar genes que potencialmente estão envolvidos em sua etiopatogenia, principalmente aqueles que influenciam a secreção de andrógenos, a ação insulínica e a composição corporal. Entretanto, nenhum gene isoladamente demonstrou exercer um efeito significativo sobre o início precoce da ativação da produção de DHEA-S pela adrenal $(26,27)$.

A Ang II, além dos efeitos sobre a pressão arterial, pode exercer influência sobre a secreção de andrógenos e na sobrevida das células produtoras desses esteróides $(28,29)$. Por este motivo, questionou-se neste estudo se alterações do gene do receptor tipo I da Ang II ( $A G T R I)$ teriam algum papel na etiologia da adrenarca precoce idiopática.

TABELA 1. Distribuição dos genótipos para os polimorfismos C573T e A1 166C do gene AGTR1 em pacientes com adrenarca precoce idiopática e grupo controle e sua relação com a história familial de síndrome metabólica.

\begin{tabular}{|c|c|c|c|c|c|c|c|}
\hline & \multirow[b]{2}{*}{ Genótipo } & \multicolumn{3}{|c|}{ PACIENTES $(n=50)$} & \multicolumn{3}{|c|}{ CONTROLES $(n=50)^{*}$} \\
\hline & & CC & CT & $\pi T$ & CC & CT & $\pi$ \\
\hline \multirow[t]{2}{*}{ C573T } & $\mathrm{N}^{\circ} \operatorname{casos}(\%)$ & $21(42,0)$ & $22(44,0)$ & $7(14,0)$ & $21(42,0)$ & $20(40,0)$ & $9(18,0)$ \\
\hline & $H F+(\%)(n=28)$ & $13(46,5)$ & $8(28,5)$ & $7(25,0)$ & - & - & - \\
\hline \multirow[t]{3}{*}{ Al166C } & Genótipo & AA & $A C$ & CC & AA & $\mathrm{AC}$ & CC \\
\hline & $\mathrm{N}^{\circ} \operatorname{casos}(\%)$ & $31(62,0)$ & $14(28,0)$ & $5(10,0)$ & $32(64,0)$ & $10(20,0)$ & $8(16,0)$ \\
\hline & $\mathrm{HF}+(\%)(\mathrm{n}=28)$ & $16(57,0)$ & $8(29,0)$ & $4(14,0)$ & - & - & - \\
\hline
\end{tabular}

n: número de indivíduos

HF+: história familial de síndrome metabólica

* Os controles não possuem história familial de síndrome metabólica 
TABELA 2. Comparação entre os genótipos para os polimorfismos C573T e A1 166C segundo os aspectos clínicos e laboratoriais dos pacientes com adrenarca precoce idiopática e distribuição dos percentis da pressão arterial segundo com os genótipos de ambos os polimorfismos.

\begin{tabular}{|c|c|c|c|c|c|c|c|c|c|}
\hline & & \multicolumn{3}{|c|}{ Polimorfismo C573T } & \multicolumn{5}{|c|}{ Polimorfismo A1 166C } \\
\hline & & $\mathrm{CC}$ & $\mathrm{CT}$ & $\pi$ & $p$ & AA & AC & $\mathrm{CC}$ & $p$ \\
\hline \multicolumn{2}{|c|}{ Idade Pubarca (DP) } & $5,6(1,3)$ & $6,2(0,7)$ & $5,9(1,0)$ & 0,40 & $5,8(1,0)$ & $6,3(0,9)$ & $5,5(1,4)$ & 0,30 \\
\hline \multicolumn{2}{|c|}{$\mathrm{ZIMC}(\mathrm{kg} / \mathrm{m} 2)$} & $1,0(1,2)$ & $0,6(1,3)$ & $-0,3(1,0)$ & 0,10 & $0,5(1,4)$ & $0,8(1,2)$ & $0,9(1,0)$ & 0,70 \\
\hline \multicolumn{2}{|c|}{ DHEA-S (ng/mL) } & 720,0 (539) & $673,0(375)$ & 873,0 (437) & 0,50 & 791,0 (391) & $579,5(552)$ & $682,5(531)$ & 0,35 \\
\hline \multicolumn{2}{|c|}{ Glicemia (mg/dL) } & $88,5(10,4)$ & $88,5(6,9)$ & $87,2(6,2)$ & 0,70 & $88,0(7,5)$ & $88,0(9,5)$ & $94,5(10,6)$ & 0,50 \\
\hline \multicolumn{2}{|c|}{ Insulinemia (UI/mL) } & $11,5(4,7)$ & $9,9(5,6)$ & $11,5(7,4)$ & 0,70 & $9,9(5,5)$ & $12,0(5,1)$ & $19,0\left(^{*}\right)$ & 0,30 \\
\hline \multicolumn{2}{|c|}{ Relação G/I } & $8,7(4,4)$ & $13,8(10,1)$ & $9,6(4,3)$ & 0,30 & $12,4(8,3)$ & $9,6(8,2)$ & $5,3\left({ }^{*}\right)$ & 0,20 \\
\hline \multicolumn{2}{|c|}{ CT (mg/dL) } & $163(24,5)$ & $156,3(22,3)$ & $138(11,4)$ & 0,10 & $152,0(20,0)$ & $165,2(29,6)$ & $152,0(5,6)$ & 0,35 \\
\hline & & CC (\%) & СT (\%) & $\Pi(\%)$ & & $A A(\%)$ & $A C(\%)$ & $\mathrm{CC}(\%)$ & \\
\hline PPA-S* & $<10$ & $6(16,3)$ & $7(18,9)$ & $1(2,7)$ & - & $9(24,4)$ & $3(8,1)$ & $2(5,4)$ & - \\
\hline$(n=37)$ & $10-90$ & $7(18,9)$ & $11(29,7)$ & $5(13,5)$ & - & $15(40,5)$ & $5(13,5)$ & $3(8,1)$ & - \\
\hline PPA-D* & $<10$ & $4(10,8)$ & $7(18,9)$ & $1(2,7)$ & - & $8(21,6)$ & $2(5,4)$ & $2(5,4)$ & - \\
\hline$(n=37)$ & $10-90$ & $9(24,4)$ & $11(29,7)$ & $5(13,5)$ & - & $16(43,3)$ & $6(16,2)$ & $3(8,1)$ & - \\
\hline
\end{tabular}

Idade pubarca: Idade (em anos) referida do início da pubarca

ZIMC: desvio-padrão do índice de massa corporal, ajustado ao sexo e idade; DHEA-S: dihidroepiandrosterona-sulfato; G/I: relação glicemia/insulina; CT: colesterol total; PPA-S= Percentil da pressão arterial sistólica; PPA-D= Percentil da pressão arterial diastólica

* Todas as crianças apresentaram o percentil da pressão arterial normal para a idade (abaixo de 90).

Além disso, a Ang II parece exercer um importante papel no metabolismo lipídico, através da inibição da lipólise, e também no metabolismo da glicose por apresentar um efeito inibidor da ação da insulina (30). Desta forma, a Ang II pode estar associada à evolução da adrenarca precoce idiopática e na freqüência com que esta se associa à síndrome metabólica.

Devido ao sistema renina-angiotensina-aldosterona ser o principal regulador da pressão arterial e do balanço adequado de água corporal e íons, vários polimorfismos do gene AGTRI foram previamente investigados com o intuito de avaliar sua correlação com a hipertensão arterial sistêmica. Bonnardeaux e cols., em 1994 (31), identificaram 5 polimorfismos deste gene: C573T, Al062G, Al166C, G1517T e Al878G; porém nenhum altera a seqüência de aminoácidos codificada. Destes polimorfismos identificados, apenas o Al166C apresentou maior freqüência em indivíduos hipertensos, quando comparados a normotensos.

Já o polimorfismo C573T encontra-se no exon 5, na região codificadora do gene $A G T R 1$, e no presente estudo este polimorfismo foi evidenciado em crianças com adrenarca precoce idiopática, porém não houve correlação dos genótipos com a apresentação clínica destes pacientes (idade da pubarca, estatura de nascimento, presença de obesidade e concentrações de 17OHP e de DHEA-S). Quando os pacientes tiveram o perfil metabólico avaliado, não houve diferença entre os exames laboratoriais realizados e os genótipos para o polimorfismo C573T; demonstrando não haver relação entre a presença do alelo polimórfico T573 e a evolução para síndrome metabólica.

Quando os pacientes foram avaliados segundo a história de síndrome metabólica na família, não houve maior freqüência do polimorfismo C573T no grupo dos pacientes com história familial positiva. Também não houve diferença entre os grupos em relação às apresentações clínica e laboratorial. Porém, não há dados suficientes na literatura sobre a freqüência deste polimorfismo em indivíduos com síndrome metabólica para a comparação destas variáveis.

Em estudo prévio, ressaltando que o sistema renina-angiotensina exerce um papel no crescimento fetal, bem como na diferenciação e proliferação celular, o polimorfismo C573T do gene AGTR I foi estudado em 370 pessoas saudáveis e normotensas (176 homens e 194 mulheres) com o objetivo de avaliar seu impacto na estatura final destes indivíduos (32). Foi identificada a relação entre menores estaturas e a presença do genótipo polimórfico TT em mulheres, mas não em homens. Este dado não foi confirmado no presente estudo, pois não houve diferença entre o desviopadrão da estatura (ZE) em meninas com adrenarca precoce idiopática, quando divididas pelos 3 genótipos (CC,CT e TT).

A freqüência do alelo polimórfico T573 entre os indivíduos do grupo controle deste estudo não foi maior que a observada em grupos controles de normotensos na França (56\%) (31), na Espanha (32) e no Reino Unido (46\%) (33).

Arq Bras Endocrinol Metab vol 50 n 5 Outubro 2006 
Como pacientes com adrenarca precoce têm maiores chances de evoluir para síndrome metabólica e assim evoluir com hipertensão arterial, o polimorfismo Al166C também foi avaliado neste estudo. Este polimorfismo foi primeiro descrito por Bonnardeaux e cols. (31), que demonstraram ser este polimorfismo mais freqüente em indivíduos hipertensos, principalmente naqueles com início de hipertensão mais precoce ou com hipertensão mais grave.

Posteriormente, outros autores também relacionaram a maior freqüência deste polimorfismo ao aumento da pressão arterial (34-37), porém em alguns grupos esta relação não foi confirmada $(38,39)$. A razão para a discrepância entre estes resultados não está clara, porém sugere que este polimorfismo possa exercer alguma influência sobre os valores pressóricos, possivelmente em grupos de alto risco para hipertensão (40).

Além da hipertensão, a freqüência do alelo C1166 foi associada a outras alterações cardiovasculares e renais, tais como hipertrofia ventricular esquerda, aumento da contração da musculatura lisa vascular, diminuição da taxa de filtração glomerular e a piora da função renal em pacientes renais crônicos e em diabéticos tipo I com pior controle glicêmico. A relação deste polimorfismo com as diversas alterações avaliadas sugere que, para elucidar o papel patofisiológico do alelo C1166, deve-se procurar a associação deste com outros genes $(40,41)$.

No presente estudo, não houve correlação do genótipo polimórfico C1166 com a história familial de hipertensão, obesidade, síndrome metabólica ou com os demais achados clínicos e hormonais. A freqüência do alelo polimórfico C1166 nos pacientes com adrenarca precoce idiopática foi semelhante à freqüência deste alelo no grupo controle. Esta freqüência em pessoas saudáveis e sem história familial para síndrome metabólica não foi maior que a observada em grupos controles de normotensos brasileiros (16\%) (42) e de outros países como França (28\%) (32), Austrália (29\%) (34), Polônia $(20 \%)$ (35) e Turquia $(25,9 \%)$ (37). Houve apenas diferença significante da freqüência do alelo C1166 do grupo controle do presente estudo, quando comparada à população de controles japonesa que apresenta uma freqüência muito baixa deste alelo $(7,8 \%)(39)$.

No presente estudo, concluiu-se que não foram encontradas mutações nos genes AGTRl e AGTR2. Apenas dois polimorfismos foram observados, C573T e Al 166C, no gene AGTRl. Estes polimorfismos não mostraram correlação significante com a evolução clínica e laboratorial dos pacientes com adrenarca pre- coce. Contudo, considera-se necessário o rastreamento de mutações dos genes AGTRl e AGTR2 em regiões não codificadoras para que se possa excluir definitivamente a influência dos mesmos na gênese da adrenarca precoce.

\section{AGRADECIMENTO}

Agradecemos ao Núcleo de Apoio à Publicação da Faculdade de Ciências Médicas da Santa Casa de São Paulo - NAP-SC - o suporte técnico-científico à publicação deste manuscrito.

\section{REFERÊNCIAS}

1. Ibanez L, Dimartino-Nardi J, Potau N, Saenger P. Premature adrenarche - normal variant or forerunner of adult disease? Endocr Rev 2000;21:671-96.

2. Ibanez L, Potau N, de Zegher F. Endocrinology and metabolism after premature pubarche in girls. Acta Paediatr Suppl 1999;88:73-7.

3. DiMartino-Nardi J. Pre- and postpuberal findings in premature adrenarche. J Pediatr Endocrinol Metab 2000; 13(suppl.5):1265-9.

4. Kater CE, Costa-Santos M. O espectro das síndromes de hipertensão esteróide na infância e adolescência. Arq Bras Endocrinol Metab 2001;45:73-86.

5. Kristiansen SB, Endoh A, Casson PR, Buster JE, Hornsby PJ. Induction of steroidogenic enzyme genes by insulin and IGF-I in cultured adult human adrenocortical cells. Steroids 1997;62:258-65.

6. Auchus RJ, Rainey WE. Adrenarche-physiology, biochemistry and human disease. Clin Endocrinol (Oxf) 2004;60:288-96.

7. Qiu J, Nelson SH, Speth RC, Wang DH. Regulation of adrenal angiotensin receptor subtypes: a possible mechanism for sympathectomy-induced adrenal hypertrophy. J Hypertens 1999: 17:933-40.

8. de Gasparo M, Catt KJ, Inagami T, Wright JW, Unger T. International union of pharmacology. XXIII. The angiotensin II receptors. Pharmacol Rev 2000;52:415-72.

9. Naruse M, Tanabe A, Sugayp T, Naruse K, Yoshimoto T, Seki T, et al. Differential roles of angiotensin receptor subtypes in adrenocortical function in mice. Life Sci 1998:63:1593-8.

10. Gasc JM, Shanmugam S, Sibony M, Corvol P. Tissue-specific expression of type 1 angiotensin II receptor subtypes. An in situ hybridization study. Hypertens 1994;24:531-7.

11. Fogo $A B$. Angiotensin receptors: beyond number one. Curr Opin Nephrol Hypertens 2004; 13:275-7.

12. Kaschina $\mathrm{E}$, Unger T. Angiotensin AT1/AT2 receptors: regulation, signalling and function. Blood Press 2003; 12:7088. 
13. Inagami T, Kambayashi Y, Ichiki T, Tsuzuki S, Eguchi S, Yamakawa T. Angiotensin receptors: molecular biology and signalling. Clin Exp Pharmacol physiol 1999:26:544-9.

14. Bergsma DJ, Ellis $C$, Kumar $C$, Nuthulaganti $P$, Kersten $H$, Elshourbagy $\mathrm{N}$, et al. Cloning and characterization of a human angiotensin II type 1 receptor. Biochem Biophys Res Commun 1992;183:989-95.

15. Furuta H, Guo DF, Inagami T. Molecular cloning and sequencing of the gene encoding human angiotensin II type 1 receptor. Biochem Biophys Res Commun 1992:183:8-13.

16. Guo DF, Furuta H, Mizukoshi M, Inagami T. The genomic organization of human angiotensin II type 1 receptor. Biochem Biophys Res Commun 1994;200:313-9.

17. Koike G, Horiushi M, Yamada T, Szpirer C, Jacob HJ, Dzau VJ. Human type 2 angiotensin II receptor gene: cloned, mapped to the $\mathrm{X}$ chromosome, and its mRNA is expressed in the human lung. Biochem Biophys Res Commun 1994:203:1842-50

18. Tissir F, Riviere M, Guo DF, Tsuzuki S, Inagami T, Levan $G$, et al. Localization of the genes encoding the three rat angiotensin II receptors, Agtrla, Agtrlb, Agtr2, and the human AGTR2 receptor respectively to rat chromosomes $17 q 12,2 q 24$ and $X q 24$ and Xq34, and the human Xq22. Cytogenet Cell Genet 1995;71:77-80.

19. Warnecke C, Willich T, Holzmeister J, Bottari SP, Fleck E, Regitz-Zagrosek $V$. Efficient transcription of the human angiotensin II type 2 receptor gene requires intronic sequence elements. Biochem J 1999;340(Pt1):17-24.

20. Langlois D, Li JY, Saez JM. Development and function of the human fetal adrenal cortex. J Pediatr Endocrinol Metab 2002;15(suppl.5):1311-22.

21. Chamoux E, Breault L, Lehoux JG, Gallo-Payet N. Involvement of the angiotensin II type 2 receptor in apoptosis during human fetal adrenal gland development. J Clin Endocrinol Metab 1999;84:4722-30.

22. Breault L, Lehoux JG, Gallo-Payet N. The angiotensin AT2 receptor is present in the human fetal adrenal gland throughout the second trimester of gestation. J Clin Endocrinol Metab 1996:81:3914-22.

23. Bocian-Sobkowska J, Wozniak W, Malendowicz LK. Postnatal involution of the human adrenal fetal zone: stereologic description and apoptosis. Endocr Res 1998;24: 969-73.

24. Stoll $M$, Unger T. Angiotensin and its AT2 receptor: new insights into an old system. Regul Pept 2001;99:175-82.

25. Vuguin $P$, Saenger P, DiMartino-Nardi J. Fasting glucose insulin ratio: a useful measure of insulin resistance in girls with premature adrenarche. J Clin Endocrinol Metab 2001:86:4618-21.

26. Witchel SF, Smith R, Tomboc M, Aston CE. Candidate gene analysis in premature pubarche and adolescent hyperandrogenism. Fertil Steril 2001;75:724-30.

27. Ibanez L, Marcos MV, Potau N, White C, Aston CE, Witchel SF. Increased frequency of the G972R variant of the insulin receptor substrate-1 (irs-1) gene among girls with a history of precocious pubarche. Fertil Steril 2002;78:1288-93.

28. Penhoat A, Ouali R, Viard I, Langlois D, Saez JM. Regulation of primary response and specific genes in adrenal cells by peptide hormones and growth factors. Steroids 1996;61:176-83.
29. Yamada T, Horiuchi M, Dzau VJ. Angiotensin II type 2 receptor mediates programmed cell death. Proc Natl Acad Sci USA 1996;93:156-60.

30. Strauzzullo P, Galletti F. Impact of the rennin-angiotensin system on lipid and carbohydrate metabolism. Curr Opin Nephrol Hypertens 2004; 13:325-33.

31. Bonnardeaux A, Davies E, Jeunemaitre X, Fery I, Charru $A$, Clauser $E$, et al. Angiotensin II type 1 receptor gene polymorphisms in human essential hypertension. Hypertension 1994:24:63-9.

32. Chaves FJ, Corella D, Sorli JV, Marin-Garcia P, Guillen M, Redon J. Polymorphisms of the renin-angiotensin system influence height in normotensive women in a Spanish population. J Clin Endocrinol Metab 2004:89:2301-5.

33. Morgan L, Crawshaw S, Baker PN, Edwards R, Broughton Pipkin F, Kalsheker N. Functional and genetic studies of the angiotensin II type 1 receptor in pre-eclamptic and normotensive pregnant women. J Hypertens 1997;15:1389-96.

34. Wang WY, Zee RY, Morris BJ. Association of angiotensin II type 1 receptor gene polymorphism with essential hypertension. Clin Genet 1997;51:31-4.

35. Dzida G, Sobstyl J, Puzniak A, Golon P, Mosiewicz J, Hanzlik J. Polymorphisms of angiotensin-converting enzyme and angiotensin II receptor type 1 genes in essential hypertension in a Polish population. Med Sci Monit 2001:7:1236-41.

36. Jiang Z, Zhao W, Yu F, Xu G. Association of angiotensin II type 1 receptor gene polymorphism with essential hypertension. Chin Med J 2001;114:1249-51.

37. Agachan B, Isbir T, Yilmaz H, Akoglu E. Angiotensin converting enzyme I/D, angiotensinogen T174M-M235T and angiotensin II type 1 receptor A 1166C gene polymorphisms in Turkish hypertensive patients. Exp Mol Med 2003:35:545-9.

38. Schmidt S, Beige J, Walla-Friedel M, Michel MC, Sharma AM, Ritz E. A polymorphism in the gene for the angiotensin II type 1 receptor is not associated with hypertension. J Hypertens 1997; 15:1385-8.

39. Ono K, Mannami T, Baba S, Yasui N, Ogihara T, Iwai N. Lack of association between angiotensin II type 1 receptor gene polymorphism and hypertension in Japanese. Hypertens Res 2003;26:131-4.

40. Duncan JA, Scholey JW, Miller JA. Angiotensin II type 1 receptor gene polymorphisms in humans: physiology and pathophysiology of the genotypes. Curr Opin Nephrol Hypertens 2001;10:111-6.

41. Miller JA, Scholey JW. The impact of renin-angiotensin system polymorphisms on physiological and pathophysiological processes in humans. Curr Opin Nephrol Hypertens 2004:13:101-6.

42. Sprovieri SRS. Estudo do polimorfismo genético do sistema renina-angiotensina na nefropatia lúpica em população brasileira, São Paulo, 2003. (tese de doutorado, Faculdade de Ciências Médicas da Santa Casa de São Paulo).

\section{Endereço para correspondência:}

Carlos Alberto Longui

Rua D. Veridiana 322/43

01238-010 São Paulo, SP

FAX: (11) 222-0628

E-mail: carlos.longui@fcmscsp.edu.br 